\title{
AFTERWORD
}

\section{The Future of Public Health and the Law: Reducing the Racial Equity Gap}

We do know that health inequities at their very core are due to racism .... There's no doubt about that. As a Black man, my status, my suit and tie don't protect me.

Dr. GEORGES BENJAMIN, executive director of the American Public Health Association (Vestal, 2020)

At the heart of this text is a focus on health equity and the role of law in protecting and promoting public health. Our goal was to present a text that not only provides a comprehensive, user-friendly overview of foundational and interventional public health law, but also highlights ways in which public health practices, policies, and laws impact health equity and health disparities.

As this book goes to press, this goal seems even more relevant and urgent than ever before. On January 30, 2020, the World Health Organization (WHO) declared the relentless coronavirus disease, COVID-19, a Public Health Emergency of International Concern (Gostin et al., 2020). Several months later, on May 25, 2020, the world watched in horror for 8 minutes and 46 seconds as George Floyd was killed by law enforcement officers on camera. In the middle of the COVID-19 pandemic, Americans organized protests, marches, demonstrations, and petitions advocating for systemic changes to protect and uplift the livelihood of America's most vulnerable populations.

While some have only one pandemic to grapple with, Black Americans are facing a double burden: the disproportionate impact of COVID-19 and systemic, structural racism. While this double burden is not new to the minority experience, it is perhaps the first time since the civil rights protests of the 1960s that Black American voices are getting a place on the international stage (Anderson, 2003). It is becoming clearer to people that although the law may have changed since the 1960s, so much of how laws are implemented and enforced has not.

Events like the killing of George Floyd-of Breonna Taylor, Manuel Ellis, James Spurlock, Ahmaud Arbery, Rashard Brooks, and on and on-have triggered in many in the Black American community a feeling of exhaustion, helplessness, anger, and hopelessness. Much of the media and political response to these events have not been trauma-informed. Trauma-informed messaging recognizes that traumatic experiences and their mental and emotional impacts tie 
closely into behavioral health problems. Much of what we saw on our social media feeds and on the news retraumatized us and others with histories of racism and discrimination-related traumas. According to one study, within a week of George Floyd's death, anxiety and depression among Black Americans were higher than any other racial or ethnic group (Fowers \& Wan, 2020).

These mental health statistics, coupled with the disproportionate burden of illness and death among Black Americans from COVID-19 (Millett et al., 2020), provide evidence of what many Black Americans in public health have been saying and what research has shown-structural racism is a public health issue. Racism structures opportunity and assigns value based on skin color, resulting in conditions that unfairly advantage some and unfairly disadvantage others. "Racism hurts the health of our nation by preventing some people the opportunity to attain their highest level of health" (Burak, 2020). We cannot reach our goals of health equity without addressing racism.

Studies show that the racism and discrimination that Black Americans experience in our daily lives create stress that affects our internal organs and overall physical health (Smedley, 2012). This results in a higher prevalence of chronic diseases such as high blood pressure, asthma, and diabetes, as well as a shorter life span. Considering maternal and child health, according to a 2019 study by the U.S. Department of Health and Human Services (DHHS) Office of Minority Health, we also know that in the Black population:

- Infant mortality is 2.3 times higher than in non-Hispanic Whites;

- Infants are 3.8 times as likely to die from complications related to low birth weight as compared to non-Hispanic White infants;

- The sudden infant death syndrome (SIDS) mortality rate is over twice that of nonHispanic Whites; and

- Mothers are 2.3 times more likely than non-Hispanic White mothers to receive late or no prenatal care.

Healthcare is just one area where racism and discrimination impact health outcomes. The reality, as seen throughout this text, is that healthcare, access, and delivery determines only about $25 \%$ of our health. The remaining $75 \%$ of what determines our health, as a population, is our total environment or ecology - this includes the social environment in which we live, work, learn, play, worship, and age (Hood et al., 2016). These social determinants of health result in upstream challenges related to, for example, limited income opportunities, lack of quality childcare, inferior schools, less safe neighborhoods, unstable housing, limited legal and social support, limited access to healthy food, poor access to transportation, and fewer community recreational facilities. The downstream effects include disproportionate rates of heart disease, stroke, cancer, diabetes, respiratory conditions, obesity, arthritis, pedestrian fatalities, and more (Merck, 2018).

This means that racial health disparities are not just the result of disparate access and treatment in the realm of healthcare. As Will Jawando, a Montgomery County (Maryland) council member, said, "whether it is police-involved killings or disparate health outcomes where [Black-American] patients can't get treatment because they are not seen as being sick, or financial redlining in certain ZIP codes, food deserts, or people of color getting hit by cars more often because their communities aren't walkable-it's all ultimately due to racism" (Vestal, 2020). Impacting infectious disease, this systemic racism has led to rapidly expanding inequity amidst the COVID-19 pandemic, impacting both risk of infection and chances of survival (Mosley \& Hagan, 2020).

As we hope this book has effectively highlighted, when you consider most public health issues and conditions, you will find striking disparities and health inequities based on determinants of health that are driven by race. Racial disparities are not the result of individual behaviors or lack of adherence to medical and healthcare guidance (Associated Press, 2020). They are the result of deeply embedded structural racism that exists across all segments of our society-from our courthouses to our hospitals, from our schools to our workplaces. 
My interest in racial health disparities is personal and professional. My first professional publication, almost 20 years ago, was a section in a book chapter where I wrote about lead poisoning, health disparities, and the law. That work opened my eyes up to how law can be used to limit exposure to a toxic substance and how implementing public health laws can positively impact health outcomes. Yet, I also learned that while these laws helped reduce the number of lead-poisoned children, this reduction served to highlight significant, continued, racial disparities in lead exposure. Even though fewer children are poisoned by lead, there are still more nonWhite kids with lead poisoning. The question for me was—and still is—why?

I have learned that the answer to that question is complex and involves the myriad upstream and downstream factors mentioned earlier. But resolving the problem of racial health inequities through public health law necessarily involves acknowledging that race is a critical social determinant of health. Perhaps it is even the most significant determinant of health.

There is an old African proverb that says that the child who is not embraced by the warmth of the village will burn it down to feel its warmth. The protests that followed George Floyd's death have been a visual depiction of this proverb in real-time. The seemingly continuous killing of unarmed Black people-right in the middle of a pandemic that has had a dramatically disparate impact on Black and Brown communities-continues to serve as a painful reminder that, for many Black Americans, belonging in this country is conditional. These events reminded many of us that far too often we do not feel the warmth of the laws and legal protections outlined in our country's founding documents, including those protections contemplated in foundational public health laws. These events also signaled to the nation that our health, our lives, our existence depend on foundational, sustainable change at the individual, community, and systemic level. If we want to see a change in the racial health equity gap, the status quo will not work. Public health law can play a role to reverse hundreds of years of racism that is built into the core of our country.

More than 200 U.S. jurisdictions (cities, counties, and states) have heard this call and declared racism a public health issue (Singh, 2020). These declarations are meant to catalyze change across all sectors of government and engender impact across all social determinants of health-criminal justice, education, healthcare, housing, transportation, budgets, taxes, economic development, and social services-all toward the goal of shrinking the health gap between Black Americans and the rest of the population.

This policy approach underscores the fact that the law itself is also a critical social determinant of health. Laws and regulations, how they are enforced, against whom they are enforced, and the structural frameworks they create have a profound effect on public health. The racism built into our system of laws, structures, and institutions has resulted in a system that significantly limits the access that Black Americans have to the services and conditions required to be healthy.

Even as states, cities, and counties declare racism as a public health issue, it will take more than a declaration or words on paper to see real change. We already have a lot of really good words on paper that say that discrimination is illegal. You have read about many of them in the pages of this textbook. So, naming the problem is a good first start. As Gary LeRoy, president of the American Academy of Family Physicians, stated, "the elimination of health disparities will not be achieved without first acknowledging racism's contribution to health and social inequalities" (LeRoy, 2020). But, it is just a start. The reality is that without financial resources, mandates, or a prescription for action written into law, it will be difficult to get to the meaningful, comprehensive, systemic change that is needed.

It cannot just be talk or words on paper. It is time for action. It is time for public health practitioners to identify and work to overcome conscious and unconscious bias in our research, our practices, and our policies. It is time to balance public health leadership across race and gender. The next generation of public health, social services, and healthcare practitioners-the readers of this book-is being called upon to lead this charge.

Leading this charge involves accepting that creating policies and programs that address the social determinants of health, health equity, or health disparities will do little to address the racial health equity gap without addressing structural, systemic racism. Looking at the social determinants, health equity, and health disparities through a lens that does not consider 
racism and discrimination, and that does not adequately name, define, or consider the effects of racism and discrimination-as has been our practice in the field-does very little to mitigate racial health disparities and has the potential to worsen existing health disparities. By focusing on structural racism in public health, you are not privileging Black people nor other people of color over other vulnerable groups. To the contrary, by understanding how racism works in our society, you can better understand the legal, structural, and economic gaps that harm all kinds of vulnerable populations. This understanding is critically important to reducing the health equity gap.

As the future of public health and public health law, it is your responsibility to use all of the tools in the public health toolbox, including foundational and interventional public health laws, to address the injustices caused by racism so that we can close the health equity gap. It is your responsibility to learn about and use tools like legal epidemiology to study the impact of our laws on public health and, more specifically, the impact of these laws and legal structures on the health of Black Americans and other people of color. This means that you will have to do more than just evaluate and understand how laws create the conditions that have a negative impact on health. You will need to be prepared to step into the muddy waters of public health advocacy around issues that fall outside of the traditional domain of public health. Policymakers do not allocate resources or implement regulations to address inequities because of their reliance on sound data (legal epidemiological or otherwise). They respond to social movements, to economic implications, to pressure. As the next generation of public health leaders, you are being asked to reimagine the discipline of public health and what it asks of us, in a post-COVID world.

The field, and the health of the public, needs this of you if we are to realize the hope that is at the core of the mission of public health: "fulfilling society's interest in assuring conditions in which people can be healthy" (Institute of Medicine (U.S.) Committee for the Study of the Future of Public Health, 1988). Not just some people, but all people.

Our hope is that the information shared in this text supports you toward that end.

Montrece McNeILL Ransom, JD, MPH

\section{REFERENCES}

Anderson, C. (2003). Eyes off the prize: The United Nations and the African American struggle for human rights, 1944-1955. Cambridge University Press.

Associated Press. (2020, June 11). Ohio lawmaker, an ER doctor, asks if hygiene is why 'colored' people get COVID-19. https://www.latimes.com/world-nation/story/2020-06-11/senator-asks-if-hygiene -is-reason-colored-people-get-virus

Burak, E. W. (2020, June 2). We need to name it: Racism is a public health crisis. Georgetown University Health Policy Institute Center for Children and Families. https://ccf.georgetown.edu/2020/06/02/ we-need-to-name-it-racism-is-a-public-health-crisis

Fowers, A., \& Wan, W. (2020, June 12). Depression and anxiety spiked among Black Americans after George Floyd's death. Washington Post. https://www.washingtonpost.com/health/2020/06/12/ mental-health-george-floyd-census

Gostin, L. O., Habibi, R., \& Meier, B. M. (2020, May 10). Has global health law risen to meet the COVID-19 challenge? Revisiting the international health regulations to prepare for future threats. Journal of Law, Medicine and Ethics, 48, 376-381. http://doi.org/10.2139/ssrn.3598165

Hood, C. M., Gennuso, K. P., Swain, G. R., \& Catlin, B. B. (2016). County health rankings: Relationships between determinant factors and health outcomes. American Journal of Preventive Medicine, 50(2), 129-135. https://doi.org/10.1016/j.amepre.2015.08.024

Institute of Medicine (U.S.) Committee for the Study of the Future of Public Health. (1988). The future of public health: Summary and recommendations. National Academies Press (U.S.). https://www .ncbi.nlm.nih.gov/books/NBK218215 
LeRoy, G. (2020, May 31). AAFP condemns all forms of racism. https://www.aafp.org/media-center/ releases-statements/all/2020/aafp-condemns-all-forms-of-racism.html

Merck, A. (2018, October 8). The upstream-downstream parable for health equity. https://salud-america .org/the-upstream-downstream-parable-for-health-equity

Millett, G. A., Jones, A. T., Benkeser, D., Baral, S., Mercer, L., Beyrer, C., Honermann, B., Lankiewicz, E., Mena, L., Crowley, J. S., Sherwood, J., \& Sullivan, P. (2020). Assessing differential impacts of COVID-19 on Black communities. Annals of Epidemiology, 47, 37-44. https://doi.org/10.1016/ j.annepidem.2020.05.003

Mosley, T., \& Hagan, A. (2020, June 22). California surgeon general: Systemic racism is linked to COVID-19 pandemic. WBUR. https://www.wbur.org/hereandnow/2020/06/22/california -surgeon-general-covid-19-racism

Singh, M. (2020, June 12). 'Long overdue': Lawmakers declare racism a public health emergency. The Guardian. https://www.apha.org/topics-and-issues/health-equity/racism-and-health/ racism-declarations

Smedley, B. D. (2012). The lived experience of race and its health consequences. American Journal of Public Health, 102(5), 933-935. https://doi.org/10.2105/AJPH.2011.300643

Vestal, C. (2020, June 15). Racism is a public health crisis, say cities and counties. Pew Trusts. https://pew .org/2AsZVRC 